\title{
Evaluación de procesos para obtener ensilaje de residuos piscícolas para alimentación animal.
}

\section{Evaluation of processes to obtain silage of fish residues in animal feed}

Recepción: 26 de mayo de 2017

Aceptación: 29 de junio de 2017
Críspulo Perea Román ${ }^{a *}$ José Luís Hoyos Concha ${ }^{b}$ Yeny Judith Garcés Caicedo ${ }^{\text {c }}$ Luz Stella Muñoz Arboleda ${ }^{\mathrm{d}}$ José Ader Gómez Peñaranda ${ }^{\mathrm{e}}$

\section{Resumen}

En el estudio se evaluaron procesos para la obtención de ensilaje de residuos de Trucha arcoíris (Oncorhynchus mykiss) como alternativa para alimentación animal; para ello se utilizaron ocho tratamientos: cuatro ensilajes químicos, vísceras enteras + ácido fórmico, vísceras enteras + ácido acético, vísceras molidas + ácido fórmico, vísceras molidas + ácido acético; y cuatro biológicos; vísceras enteras + melaza, vísceras enteras + harina de yuca, vísceras molidas + melaza y vísceras molidas + harina de yuca; bajo un diseño completamente al azar. Las variables determinadas fueron $\mathrm{pH}$, acidez titulable, consistencia, perfil microbiológico y la caracterización nutricional mediante análisis de composición química y pruebas de digestibilidad in vitro. Para el $\mathrm{pH}$, los tratamientos con adición de ácido fórmico presentaron valores inferiores (3.26); para la acidez titulable, los tratamientos con inclusión de melaza generaron porcentajes más altos (3.78 y $3.56 \%)$, los ensilados preparados con vísceras enteras lograron un grado de licuefacción mayor $(9.75-20.38 \mathrm{~cm} / 30 \mathrm{~s})$, la digestibilidad in vitro de la materia seca de los ensilajes estuvo por encima del $96 \%$ y esta fue equivalente a la encontrada en la harina de pescado. Los ensilajes constituyen una alternativa de buena calidad para alimentación animal debido al contenido de nutrientes que presentan.

Palabras clave: caracterización nutricional, ensilaje biológico, ensilaje químico, residuos de pescado.

a Ph.D. Vicerrectoría de investigación, Facultad de Ciencias Agrarias, Universidad del Cauca.

* Autor de correspondencia: cperear@unal.edu.co

b M.Sc. Departamento de agroindustria, Facultad de Ciencias Agrarias, Universidad del Cauca

c M.Sc. Vicerrectoría de investigación, Facultad de Ciencias Agrarias, Universidad del Cauca.

d Ph.D. Departamento de Ciencia Animal, Facultad de Ciencias Agrarias, Universidad Nacional de Colombia sede Palmira.

e Ph.D. Departamento de Ciencia Animal, Facultad de Ciencias Agrarias, Universidad Nacional de Colombia sede Palmira. 


\begin{abstract}
The study evaluated processes to obtain silage of rainbow trout (Oncorhynchus mykiss) as an alternative in animal feed. Eight treatments were used: four chemical silages, whole viscera with formic acid, whole viscera more acetic acid, viscera milled with formic acid, viscera milled more acetic acid and four biological: whole viscera more molasses, whole viscera with cassava meal, milled viscera more molasses and viscera milled with cassava meal. The design was completely random. The determined variables were $\mathrm{pH}$, titrated acidity, consistency, microbiological profile and nutritional characterization by chemical composition analysis and in vitro digestibility tests. The $\mathrm{pH}$ in the treatments with addition of formic acid presented lower values (3.26); Titrated acidity in treatments including molasses generated higher percentages (3.78 and 3.56\%), Silages prepared with whole viscera achieved a higher degree of liquefaction $(9.75-20.38 \mathrm{~cm} / 30 \mathrm{~s})$, The in vitro digestibility of dry matter of silage was above $96 \%$, equivalent to that found in fish meal. Silages are an alternative of good quality for animal feed due to the content of nutrients that they present.
\end{abstract}

Keywords: Nutritional characterization, biological silage, chemical silage, fish waste. 


\section{Introducción}

La acuicultura en Colombia, es una de las actividades productivas del sector agropecuario con mayor viabilidad y potencialidad de crecimiento económico. En el departamento del Cauca, la mayor producción de Trucha arcoíris (Oncorhynchus mykiss, Walbaum, 1792) es realizada por pequeños y medianos piscicultores, quienes se han agremiado conformando la Asociación productora y comercializadora de productos acuícolas y agrícolas de Silvia APROPESCA, la cual genera 193.6 Ton/año de residuos producto del eviscerado que no están siendo aprovechados, y su disposición inadecuada genera considerables impactos ambientales, por lo que se deben buscar alternativas viables para reducir la cantidad de residuos [1].

Una solución posible es aprovecharlos mediante procesos de bioconversión a través de fermentación láctica o empleando sustancias químicas orgánicas, transformándolos en ensilados de pescado, dando así, la posibilidad de incluirlos como suplemento en la formulación de raciones para animales, debido a que poseen una composición nutricional apreciable, cuyas proteínas son de un elevado valor biológico y una alta digestibilidad, lo cual proporciona un gran beneficio en la alimentación animal. A nivel mundial, se están buscando nuevas alternativas nutricionales para producir proteína a bajo costo y hacer que la producción de alimentos sea más sostenible [2].

Los ensilajes obtenidos a partir de residuos de pescado, están siendo ampliamente utilizados en alimentación animal, principalmente en especies menores. Se ha evaluado el ensilaje preparado a partir de sardinas (Sardinella longiceps) como sustituto parcial de la harina de soja en dietas para pollos de engorde [3]. En Trucha arcoíris (Oncorhynchus mykiss) estudiaron el crecimiento alimentando con pellets elaborados a partir de ensilaje de residuos de pescado [4]. En juveniles de cobia (Rachycentron canadum) se evaluó la digestibilidad y el crecimiento al alimentarlos con proteína de ensilaje [5]. También se estudió la utilización de ensilaje biológico de pescado en el comportamiento y las características de calidad de la carne de codornices (Coturnix coturnix japonica) [6].

Por lo anterior, y dado a la necesidad de buscar alternativas de uso que permitan disminuir el impacto ambiental ocasionado por los residuos piscícolas, el objetivo de este estudio fue evaluar las mejores condiciones para la obtención de ensilajes y a su vez valorar sus características nutricionales.

\section{Materiales y métodos}

Localización. El estudio fue realizado en el laboratorio de Biotecnología de la Universidad del Cauca (Popayán) y en el laboratorio de Nutrición Animal de la Universidad Nacional de Colombia sede Palmira, Colombia. Los procesos para obtención de ensilaje se realizaron en el laboratorio de Biotecnología de la Universidad del Cauca y la caracterización nutricional en el laboratorio de Nutrición Animal de la Universidad Nacional de Colombia sede Palmira.

Material biológico. En la investigación se utilizaron vísceras de Trucha arcoíris (Oncorhynchus mykiss). Las vísceras utilizadas para la preparación de los ensilajes fueron obtenidas en la asociación piscícola APROPESCA (Asociación productora $\mathrm{y}$ comercializadora de productos acuícolas y agrícolas de Silvia), localizada en el municipio de Silvia departamento del Cauca, Colombia.

Preparación de los ensilajes. En el ensayo fueron evaluados ocho tratamientos: cuatro ensilajes químicos: VEAF (vísceras enteras + ácido fórmico), VEAA (vísceras enteras + ácido acético), VMAF (vísceras molidas + 
ácido fórmico), VMAA (vísceras molidas + ácido acético); y cuatro biológicos: VEME (vísceras enteras + melaza), VEHY (vísceras enteras + harina de yuca), VMME (vísceras molidas + melaza) y VMHY (vísceras molidas + harina de yuca).

Para la preparación de los ensilajes, las vísceras fueron homogenizadas mediante molienda a través de un molino industrial marca JAVAR, en el caso de los tratamientos que se utilizaron molidas. Posteriormente, se pesaron y mezclaron con harina de yuca (20\%) variedad HMC-1, o melaza comercial (15\%); $0,25 \%$ de benzoato de sodio, $0,1 \%$ de Butilhidroxitolueno - BHT, 5\% de inóculo (medio con Lactobacillus plantarum liofilizado - B 2A SACCO) en el caso del biológico [7]; y 2,5\% de ácido fórmico o acético al $85 \% \mathrm{~m} / \mathrm{v}$ en el caso del químico. Los ensilajes fueron almacenados en proporciones de $2 \mathrm{~kg}$ por unidad experimental en recipientes plásticos cerrados con un espacio de cabeza del 30\% [8], a temperatura constante de $15^{\circ} \mathrm{C}$ para simular la temperatura promedio del municipio de Silvia Cauca.

Seguimiento de los ensilajes. Las variables de respuesta analizadas para el seguimiento de los ensilajes fueron: potencial de hidrógeno ( $\mathrm{pH}$ ) y acidez titulable (ATT) cada 3 días [8], consistencia o grado de licuefacción (CST) cada 4 días [9]. El perfil microbiológico se analizó mediante el recuento de bacterias ácido lácticas (BAL), mesófilos aerobios (MSAB), coliformes totales (COLITL), mohos y levaduras (MHLVD) al inicio y final del estudio $[10,11]$.

El valor de $\mathrm{pH}$ de los ensilados de pescado debe ser inferior a 4,5; de esta forma, se garantiza un adecuado proceso de fermentación y de estabilidad del mismo. Además, la rapidez con que el ensilado llegue al $\mathrm{pH}$ óptimo garantiza mayor calidad en cuanto a conservación de nutrientes o mejoramiento de características nutricionales [12]. Debido a lo anterior, se realizó un estudio preliminar durante 21 días, para determinar el tiempo óptimo de estabilización del producto; el $\mathrm{pH}$ y la ATT se midieron cada tres días; la consistencia se registró cada cuatro días y el perfil microbiológico al inicio y final del estudio. Evidenciándose que para los ensilajes químicos el tiempo óptimo fue de 12 días y para los biológicos 18 días.

Caracterización nutricional de los ensilajes. La muestra para la caracterización nutricional fue tomada en el tiempo óptimo de cada ensilaje; para ello se determinó el contenido de materia seca (MS) y cenizas por gravimetría [13], proteína cruda (PC) por el método Kjeldahl [14], perfil de aminoácidos por cromatografía liquida de alta precisión - HPLC [15], extracto etéreo (EE) por gravimetría [13], perfil de ácidos grasos por cromatografía de gases de alta precisión HPLC [16], fibra en detergente neutro (FDN) por Van Soest [17], energía bruta (EB) con bomba calorimétrica de chaqueta $\mathrm{CAL} 2 \mathrm{k}{ }^{\circledR}$ [18], y la digestibilidad enzimática in vitro de la materia seca (DIVMS), utilizando pepsina y pancreatina porcina comercial [19], a las muestras de ensilajes (químico y biológico) y la harina de pescado comercial (HP) para su comparación.

\section{Diseño experimenta y análisis estadístico.}

Se utilizó un diseño completamente al azar (DCA), y se analizaron ocho tratamientos. Para las variables $\mathrm{pH}$, ATT, CST y perfil microbiológico se utilizaron cuatro réplicas y para la DIVMS seis. Cada réplica (recipiente con $2 \mathrm{~kg}$ de ensilaje) se tomó como una unidad experimental.

Las variables determinadas, se analizaron mediante análisis de varianza (ANOVA). Se utilizó el Test de Duncan [20] para la comparación de medias $(P<0.05)$. Se empleó el programa SAS (Statistical Analysis System) versión 9.4. 


\section{Resultados y discusión}

\section{1. $\mathrm{pH}$, acidez titulable, consistencia $\mathrm{y}$ perfil microbiológico}

Los resultados obtenidos en las variables de seguimiento de los ensilajes se presentan en la tabla 1 .

Los tratamientos presentaron diferencias significativas $(P<0.05)$ para cada una de las variables evaluadas.

Se observó que los tratamientos con adición ácido fórmico (VEAF y VMAF) presentaron valores significativamente inferiores de $\mathrm{pH}$ en comparación con los de ácido acético (VEAA y VMAA) (ver tabla 1). De igual forma se evidencia que los ensilajes con melaza (VEME y VMME) presentan valores de $\mathrm{pH}$ menores en comparación con los que se adicionó harina de yuca como fuente de carbono (VEHY y VMHY). El ensilaje químico presenta mejores condiciones en cuanto al $\mathrm{pH}$, lo cual podría deberse a la fuerza del ácido en solución que se conoce como pka y a su rápido efecto, mientras que en el ensilaje biológico la producción de ácido láctico depende del crecimiento paulatino de las bacterias [21].

En general, los ensilajes químicos de vísceras de trucha y los ensilajes biológicos de vísceras de trucha presentaron valores de $\mathrm{pH}$ por debajo de 4,50 generándose rápidamente el descenso, lo cual trae como resultado la disminución de una posible contaminación por microorganismos que causan putrefacción. Es de resaltar que un $\mathrm{pH}$ por debajo de 4,5 produce la suficiente acidez para impedir el crecimiento de bacterias indeseables que afectan la calidad de los ensilados o la descomposición de los mismos [22].

Resultados similares para el $\mathrm{pH}$ han sido reportados en ensayos con ensilaje biológico

Tabla 1. Valores de potencial hidrógeno (pH), acidez titulable (ATT), consistencia (CST), mesófilos aerobios (MSAB), bacterias acido lácticas (BAL), mohos y levaduras (MHLVD) y coliformes totales (COLITL) obtenidos en los ensilajes químicos a los 12 días y biológicos a los 18 días de evaluación.

\begin{tabular}{cccccccc}
\hline Tratamientos & $\mathbf{p H}$ & ATT (\%) & CST (cm/30s) & $\begin{array}{c}\text { MSAB } \\
\text { (UFC/g) }\end{array}$ & \multicolumn{1}{c}{$\begin{array}{c}\text { BAL } \\
\text { (UFC/g) }\end{array}$} & $\begin{array}{c}\text { MHLVD } \\
\text { (UFC/g) }\end{array}$ & $\begin{array}{c}\text { COLITL } \\
\text { (NMP/g) }\end{array}$ \\
\hline $\mathrm{VEAF}^{1}$ & $3.26 \pm 0.01^{\mathrm{e}}$ & $3.10 \pm 0.04^{\mathrm{d}}$ & $20.10 \pm 1.10^{\mathrm{b}}$ & $0.0 \pm 0.00^{\mathrm{d}}$ & $0.0 \pm 0.00^{\mathrm{d}}$ & $0.0 \pm 0.00^{\mathrm{c}}$ & $0.0 \pm 0.00^{\mathrm{b}}$ \\
$\mathrm{VEAA}^{2}$ & $4.23 \pm 0.01^{\mathrm{c}}$ & $3.03 \pm 0.06^{\mathrm{d}}$ & $21.08 \pm 0.30^{\mathrm{b}}$ & $0.0 \pm 0.00^{\mathrm{d}}$ & $0.0 \pm 0.00^{\mathrm{d}}$ & $0.0 \pm 0.00^{\mathrm{c}}$ & $0.0 \pm 0.00^{\mathrm{b}}$ \\
$\mathrm{VMAF}^{3}$ & $3.26 \pm 0.20^{\mathrm{e}}$ & $3.16 \pm 0.03^{\mathrm{d}}$ & $16.90 \pm 0.92^{\mathrm{c}}$ & $0.0 \pm 0.00^{\mathrm{d}}$ & $0.0 \pm 0.00^{\mathrm{d}}$ & $0.0 \pm 0.00^{\mathrm{c}}$ & $0.0 \pm 0.00^{\mathrm{b}}$ \\
$\mathrm{VMAA}^{4}$ & $4.26 \pm 0.01^{\mathrm{c}}$ & $3.31 \pm 0.07^{\mathrm{c}}$ & $13.50 \pm 1.20^{\mathrm{d}}$ & $0.0 \pm 0.00^{\mathrm{d}}$ & $0.0 \pm 0.00^{\mathrm{d}}$ & $0.0 \pm 0.00^{\mathrm{c}}$ & $0.0 \pm 0.00^{\mathrm{b}}$ \\
$\mathrm{VEME}^{5}$ & $4.07 \pm 0.04^{\mathrm{d}}$ & $3.78 \pm 0.04^{\mathrm{a}}$ & $20.38 \pm 0.83^{\mathrm{b}}$ & $8.6 \times 10^{8} \pm 308^{\mathrm{c}}$ & $6.9 \times 10^{8} \pm 189^{\mathrm{c}}$ & $6.1 \times 10^{5} \pm 189^{\mathrm{b}}$ & $0.0 \pm 0.00^{\mathrm{b}}$ \\
$\mathrm{VEHY}^{6}$ & $4.50 \pm 0.06^{\mathrm{a}}$ & $2.52 \pm 0.09^{\mathrm{f}}$ & $9.75 \pm 0.21^{\mathrm{e}}$ & $1.7 \times 10^{9} \pm 223^{\mathrm{a}}$ & $1.6 \times 10^{9} \pm 391^{\mathrm{b}}$ & $2.9 \times 10^{5} \pm 157^{\mathrm{bc}}$ & $15.0 \pm 0.00^{\mathrm{a}}$ \\
$\mathrm{VMME}^{7}$ & $4.07 \pm 0.02^{\mathrm{d}}$ & $3.56 \pm 0.20^{\mathrm{b}}$ & $22.35 \pm 0.75^{\mathrm{a}}$ & $9.6 \times 10^{8} \pm 460^{\mathrm{c}}$ & $6.7 \times 10^{8} \pm 288^{\mathrm{c}}$ & $2.0 \times 10^{6} \pm 80^{\mathrm{a}}$ & $0.0 \pm 0.00^{\mathrm{b}}$ \\
$\mathrm{VMHY}^{8}$ & $4.35 \pm 0.01^{\mathrm{b}}$ & $2.75 \pm 0.02^{\mathrm{e}}$ & $8.23 \pm 0.19^{\mathrm{f}}$ & $1.3 \times 10^{9} \pm 85^{\mathrm{b}}$ & $2.3 \times 10^{9} \pm 59^{\mathrm{a}}$ & $2.9 \times 10^{5} \pm 16^{\mathrm{bc}}$ & $0.0 \pm 0.00^{\mathrm{b}}$ \\
$\begin{array}{c}\mathrm{ANOVA} \\
\mathrm{Pr}>\mathrm{F}\end{array}$ & 0.0001 & 0.0001 & 0.0001 & 0.0001 & 0.0001 & 0.0001 & 0.0001 \\
\hline
\end{tabular}

Letras diferentes en la misma columna, difieren estadísticamente $(P<0.05) .{ }^{1}$ Vísceras enteras + ácido fórmico - VEAF. ${ }^{2}$ Vísceras enteras + ácido acético - VEAA. ${ }^{3}$ Vísceras molidas + ácido fórmico - VMAF. ${ }^{4}$ Vísceras molidas + ácido acético - VMAA. ${ }^{5}$ Vísceras enteras + melaza VEME. ${ }^{6}$ Vísceras enteras + harina de yuca - VEHY. ${ }^{7}$ Vísceras molidas + melaza - VMME. ${ }^{8}$ Vísceras molidas + harina de yuca - VMHY. 
de subproductos de tilapia [7, 23], en evaluaciones con ensilaje químico de residuos de sardinas [24] y en estudios con ensilaje químico de residuos de tilapia [23].

Para la acidez titulable - ATT, se observó que en los ensilajes biológicos los tratamientos que tenían inclusión de melaza presentaron porcentajes significativamente mayores que los demás, existiendo diferencias entre ellos debido al estado de las vísceras (tabla 1), siendo mayor para las enteras; lo anterior podría estar asociado con el mayor contenido de bacterias endógenas en las vísceras enteras y a la gran disponibilidad de azucares fermentables presentes en la melaza que contribuyen significativamente a la rapidez de la acidificación [25]. En los ensilajes químicos, el tratamiento que contenía vísceras molidas y ácido acético, presentó significativamente mayor acidez titulable en comparación con los demás; lo cual se debe a que el ácido acético contribuye a un aumento de la acidez en comparación con el fórmico [26].

Se han reportado resultados similares para la acidez titulable en investigaciones realizadas con ensilaje biológico de subproductos de tilapia [7, 27], y en estudios con ensilaje químico de residuos de sardinas [28].

Para la consistencia, se observó que en los ensilajes químicos donde se utilizaron vísceras enteras presentaron un grado de licuefacción significativamente mayor que los demás (tabla 1). En el caso del ensilaje biológico los tratamientos con inclusión de melaza registraron un grado de licuefacción significativamente mayor en comparación con los que tenían harina de yuca. El alto grado de licuefacción presentado en los ensilajes con vísceras enteras, podría deberse al rápido inicio de la acción de las enzimas proteolíticas [27].

En ensilaje de residuos de pescado reportan que se presentó la máxima licuefacción (24 $\mathrm{cm} / 30 \mathrm{~s}$ ) entre las 12 a 24 horas de evaluación [9]. En estudios realizados en ensilaje de tilapia registraron una consistencia pastosa, similar a los del presente estudio [27].

En el perfil microbiológico, los ensilajes químicos no presentaron recuentos de microorganismos. En los biológicos, el ensilaje de VEHY reporto recuentos de coliformes totales y mayor número de mesófilos aerobios, VMHY presentó el mayor número de bacterias ácido lácticas y VMME mostró un recuento superior de mohos y levaduras, el mayor recuento microbiológico presentado en los ensilajes biológicos podría estar asociado con la fuente de carbono adicionada. El ensilaje biológico requiere la adición de carbohidratos altamente fermentables para facilitar la acción de las bacterias ácido lácticas; las cuales utilizan como fuente de energía los azúcares, facilitando su rápido crecimiento y presentándose la fermentación que produce un ambiente anaeróbico y convierte a esta en la población predominante, con la consecuente disminución del $\mathrm{pH}$ que indica una buena fermentación y el incremento de la acidez [6].

Las condiciones microbiológicas del ensilado son decisorias, debido a que a mayor concentración de microorganismos indeseables, menor será la estabilidad, inocuidad y calidad nutricional del ensilado de pescado. Los microorganismos producen degradación de los nutrientes, formación de compuestos tóxicos, aumento de $\mathrm{pH}$ y descomposición del producto; estas condiciones microbiológicas pueden ser disminuidas obteniendo $\mathrm{pH}$ bajo en el ensilado y rapidez con la cual el ensilado llegue al $\mathrm{pH}$ por debajo de 4,5 [12].

Resultados similares para el perfil microbiológico han sido reportados en estudios con ensilaje biológico de residuos del procesamiento de sardinas [28] y del eviscerado de tilapia [7]. 
En general, los ensilajes químicos presentaron mejor comportamiento en el $\mathrm{pH}$, acidez titulable y perfil microbiológico en comparación con los biológicos. No se evidenciaron diferencias en los parámetros evaluados entre las vísceras enteras $\mathrm{y}$ molidas. Los tratamientos con adición de ácido fórmico generaron valores de $\mathrm{pH}$ más bajos en comparación con los de acético. Los ensilajes con adición de melaza mostraron mejor comportamiento en comparación con los de harina de yuca.

Según los resultados anteriores, el mejor proceso para la obtención de ensilaje químico de residuos de trucha, es la utilización de vísceras enteras + ácido fórmico (VEAF) y para la obtención de ensilaje biológico, es el uso de vísceras enteras + melaza (VEME); por lo que se seleccionaron estos para la caracterización nutricional.

\subsection{Caracterización nutricional}

Los ensilajes seleccionados para la caracterización nutricional fueron comparados con la harina de pescado comercial (tabla 2).

La composición nutricional del ensilaje químico y biológico evaluados fue similar, existiendo pocas diferencias en el contenido de proteína cruda, extracto etéreo, cenizas y energía bruta (tabla 2).

Los ensilados químico y biológico presentan un alto porcentaje de extracto etéreo, debido probablemente al contenido de grasa que poseen alrededor las vísceras y los órganos internos. También se resalta el contenido de proteína cruda (superior al 23\%) por lo que pueden ser considerados como materias primas con gran potencial proteico y energético. Además, su gran aporte de energía bruta y metabolizable es debido al alto contenido de grasa y proteína presentes en los ensilados, los cuales aportan mayor cantidad de kilocalorías por kilogramo en comparación a los carbohidratos.

Los ensilajes de vísceras de trucha presentaron bajos contenidos de cenizas (tabla 2), lo anterior se debe probablemente a que no presentan componentes óseos. Los bajos valores de fibra en detergente neutro en los ensilados químico y biológico podría deberse a que son subproductos de origen animal los cuales no poseen pared celular, el contenido encontrado se debe a los residuos de alimento (celulosa, hemicelulosa y lignina) que se encontraban en el tracto digestivo

Tabla 2. Composición química de los ensilajes y de la harina de pescado.

\begin{tabular}{lcccc}
\hline \multicolumn{1}{c}{ Nutrientes } & $\begin{array}{c}\text { Ensilaje } \\
\text { Químico }^{\mathrm{I}}\end{array}$ & $\begin{array}{c}\text { Ensilaje } \\
\text { biológico }^{\mathrm{II}}\end{array}$ & $\begin{array}{c}\text { Harina de } \\
\text { pescado }\end{array}$ & $\begin{array}{c}\text { ANOVA } \\
\text { Pr }>\text { F }\end{array}$ \\
\hline Materia seca - MS \% & $38.43 \pm 3.19^{\mathrm{c}}$ & $43.29 \pm 2.45^{\mathrm{b}}$ & $88.62 \pm 0.37^{\mathrm{a}}$ & 0.0001 \\
Proteína cruda - PC \% & $25.10 \pm 0.44^{\mathrm{b}}$ & $23.90 \pm 1.57^{\mathrm{b}}$ & $66.10 \pm 0.47^{\mathrm{a}}$ & 0.0001 \\
Extracto etéreo - EE \% & $58.36 \pm 0.53^{\mathrm{a}}$ & $57.03 \pm 0.74^{\mathrm{b}}$ & $10.76 \pm 0.27^{\mathrm{c}}$ & 0.0001 \\
Cenizas \% & $5.74 \pm 0,09^{\mathrm{b}}$ & $5.20 \pm 0.23^{\mathrm{c}}$ & $21.20 \pm 0.08^{\mathrm{a}}$ & 0.0001 \\
Fibra en detergente neutro - FDN \% & $0.93 \pm 0.36^{\mathrm{b}}$ & $1.52 \pm 0.29^{\mathrm{a}}$ & $0.30 \pm 0.02^{\mathrm{c}}$ & 0.0041 \\
DIVMS \% & $99.13 \pm 0.58^{\mathrm{a}}$ & $98.59 \pm 1.18^{\mathrm{a}}$ & $99.49 \pm 0.29^{\mathrm{a}}$ & 0.2096 \\
Elementos no nitrogenados - ELN $\%$ & $9.90 \pm 0.49^{\mathrm{a}}$ & $12.35 \pm 2.08^{\mathrm{a}}$ & $1.63 \pm 0.43^{\mathrm{b}}$ & 0.0001 \\
Energía Bruta - EB kcal/kg & $6525 \pm 288.68^{\mathrm{a}}$ & $6797 \pm 152.61^{\mathrm{a}}$ & $4218 \pm 28.60^{\mathrm{b}}$ & 0.0001 \\
Energía metabolizable - EM ${ }^{3} \mathrm{kcal} / \mathrm{kg}$ & $5383 \pm 29.14^{\mathrm{a}}$ & $5239 \pm 89.23^{\mathrm{b}}$ & $2899 \pm 17.98^{\mathrm{c}}$ & 0.0001 \\
\hline
\end{tabular}

Letras diferentes en la misma fila, difieren estadísticamente $(\mathrm{P}<0.05)$. ${ }^{\mathrm{I}}$ vísceras enteras + ácido fórmico (VEAF), ${ }^{\mathrm{II}}$ vísceras enteras + melaza (VEME). ${ }^{1}$ Digestibilidad in vitro de la materia seca - DIVMS. ${ }^{2} \mathrm{ELN}=100-(\mathrm{PC}+$ Cenizas $+\mathrm{EE}+\mathrm{FDN}) \cdot{ }^{3} \mathrm{EM}=\{(31,02 * \mathrm{PC})+(78,87 * \mathrm{EE})\}$ 
de los peces, y en el caso del biológico, a la adición de melaza y harina de yuca en estos. De igual manera sucede con los elementos no nitrogenados, el leve aumento presentado en el ensilaje biológico se debe a la adición de melaza, harina de yuca e inóculo en su preparación [21].

Valores similares en el contenido de materia seca, proteína cruda, extracto etéreo, cenizas y fibra, han sido reportados en ensilaje químico de residuos de trucha [2] y ensilaje biológico de vísceras de trucha [29]. Los resultados obtenidos son superiores a los citados en ensilaje de vísceras de pescado de río [30].

Al comparar la digestibilidad del ensilaje químico y biológico con la muestra de harina de pescado comercial, no se presentaron diferencias significativas (tabla 2); lo anterior podrá estar relacionado con que las materias primas proteicas originarias de residuos y tejidos de animales presentan altos porcentajes de digestibilidad [31].

Valores similares han sido reportados en estudios con ensilaje biológico de vísceras de tilapia [31], en ensayos con ensilaje químico y biológico preparados con desecho del fileteado de tilapia [21] y con ensilaje de residuos de peces marinos [2].

De manera general, al comparar los contenidos de los diferentes aminoácidos, se evidencia una disminución en el ensilaje biológico en relación con el químico (tabla 3); esto podría deberse a la desaminación oxidativa de los aminoácidos libres por bacterias capaces de multiplicarse a temperaturas menores o iguales a la del ambiente, que causan su reducción, generando al mismo tiempo amonio [21]

En cuanto a los aminoácidos esenciales, los ensilajes evaluados presentaron mayor contenido de valina, isoleucina, leucina, fenilalanina, treonina y arginina en comparación con la harina de pescado; y similares en el contenido de metionina e histidina (tabla 3 ).

Resultados similares para el perfil de aminoácidos han sido reportados en evaluaciones con ensilaje biológico de residuos de pescado para tilapia nilótica [32], en ensilaje químico y biológico de residuos de pescado para juveniles de cobia [5] y para tilapia roja [33].

Tabla 3. Composición de aminoácidos de los ensilajes de vísceras de trucha y la harina de pescado (g/100 g de proteína).

\begin{tabular}{lccc}
\hline \multicolumn{1}{c}{ Aminoácidos } & Ensilaje químico & & \\
& & Ensilaje biológico $^{\text {II }}$ & Harina de pescado $^{\text {III }}$ \\
\hline Valina & 4.41 & 3.89 & 3.20 \\
Metionina & 3.30 & 3.10 & 4.00 \\
Lisina & 1.97 & 0.99 & 5.00 \\
Isoleucina & 3.28 & 2.90 & 2.20 \\
Leucina & 5.35 & 4.70 & 3.90 \\
Fenilalanina & 6.93 & 6.34 & 5.10 \\
Triptófano & 0.00 & 0.00 & 0.74 \\
Histidina & 2.33 & 0.83 & 1.80 \\
Treonina & 3.82 & 3.29 & 6.20 \\
Arginina & 8.58 & 7.34 & 6.00 \\
Prolina & 4.94 & 4.42 & 3.20 \\
Tirosina & 0.76 & 0.57 & 6.50 \\
Alanina & 5.38 & 4.75 & 4.50 \\
Serina & 2.19 & 2.04 & 9.00 \\
Ácido Aspártico & 4.27 & 4.10 & 13.60 \\
Ácido Glutámico & 2.31 & 2.31 & \\
\hline
\end{tabular}

IVísceras enteras + ácido fórmico (VEAF), ${ }^{\mathrm{II}}$ vísceras enteras + melaza (VEME), ${ }^{\mathrm{III}} \mathrm{NRC}$, 1981; harina de pescado con $61 \%$ de proteína bruta 
Los ensilajes evaluados presentan altos porcentajes de ácidos grasos insaturados (tabla 4). Debido al gran contenido de ácidos grasos poliinsaturados que presentan los ensilajes, estos pueden ser utilizados como sustituto del aceite de pescado comercial o los de origen vegetal en las dietas para la alimentación animal; además, la solubilización excesiva de la proteína puede ser reducida por los lípidos del ensilaje, lo que puede mejorar su calidad [34].

Los ensilajes evaluados, presentaron un perfil de ácidos grasos similar al de la harina de pescado; resaltando altos porcentajes principalmente de oleico, palmitico y linoleico. Laharina de pescado presenta mayorcontenido de ácidos grasos poliinsaturados, en especial docosahexaenoico y eicosapentaenóico.

Los peces requieren tanto omega 3 al igual que omega 6 ; los omega 6 presentan mejor efecto promotor del crecimiento. Sin embargo, los omega 3 son importantes en la alimentación ya que se destacan en la formación de membranas de las células y permeabilidad de la misma; conforman las células nerviosas; se convierten en prostaglandinas, y son importantes en el sistema cardiovascular, inmunológico, digestivo, reproductivo y poseen efectos antiinflamatorios [35]; 10 que nos indica que el ensilaje es una buena alternativa para alimentación piscícola.

Resultados similares para el perfil de ácidos grasos han sido reportados en ensilaje biológico de vísceras de trucha [29], y con ensilaje químico y biológico de residuos pesqueros [33].

\section{Conclusiones}

Los ensilajes químicos presentaron valores de $\mathrm{pH}$ más bajos en comparación con los ensilajes biológicos, porcentajes de digestibilidad in vitro de la materia seca ligeramente superiores y no registraron presencia de microorganismos. Se resalta que el mejor proceso para la obtención de ensilaje de residuos de trucha, es la utilización de vísceras enteras + ácido fórmico.

Para obtener ensilaje de vísceras de trucha no se requiere realizar molienda, a los 12 días de proceso se obtiene un producto estable y

Tabla 4. Composición de ácidos grasos de los ensilajes de vísceras de trucha y la harina de pescado ( $\mathrm{g} / 100 \mathrm{~g}$ de aceite).

\begin{tabular}{lccc}
\hline \multicolumn{1}{c}{ Ácidos grasos } & Ensilaje químico & Ensilaje biológicoII $^{\text {II }}$ & Harina de pescado $^{\text {III }}$ \\
\hline Oleico C18:1n-9 & 37.44 & 36.08 & 25.0 \\
Palmítico C16:0 & 19.11 & 18.97 & 19.0 \\
Linoleico C18:2n-6 & 16.96 & 17.57 & 7.8 \\
Palmitoleico C16:1n-7 & 6.65 & 6.67 & 5.0 \\
Esteárico C18:0 & 5.42 & 5.26 & 20.4 \\
Docosahexaenoico C22:6n-3 & 2.46 & 2.85 & 3.0 \\
Mirístico C14:0 & 1.94 & 1.80 & 1.5 \\
Linolenico C18:3n-3 & 1.49 & 1.54 & 2.5 \\
Gadoleico C20:1n-9 & 1.48 & 1.44 & 3.5 \\
Araquidónico C20:4n-6 & 0.73 & 0.80 & 1.2 \\
Docosapentaenóico C22:5n-3 & 0.41 & 0.48 & 27.00 \\
Eicosapentaenóico C20:5n-3 & 0.45 & 0.39 & 64.10 \\
Ácidos grasos Saturados & 26.15 & 26.77 & 34.50 \\
Ácidos grasos Insaturados & 73.85 & 73.23 & 29.60 \\
Ácidos grasos Monoinsaturados & 46.80 & 44.78 & 24.83 \\
Ácidos grasos Poliinsaturados & 24.07 & & \\
\hline
\end{tabular}

IVísceras enteras + ácido fórmico (VEAF), ${ }^{\mathrm{II}}$ vísceras enteras + melaza (VEME), ${ }^{\mathrm{II}} \mathrm{Blas}$ et al. 2010; Tablas FEDNA de composición y valor nutritivo de alimentos para la fabricación de piensos compuestos. 
con un grado de licuefacción similar al de las vísceras molidas; lo que permite ahorrar tiempo, mano de obra, equipos y costo en el proceso.

Los ensilajes evaluados presentaron altos contenidos de energía y de nutrientes, especialmente en lo relacionado con ácidos grasos insaturados (oleico, palmitico y linoleico) y aminoácidos esenciales (valina, isoleucina, leucina, fenilalanina, treonina $\mathrm{y}$ arginina), destacándolos como una alternativa de alta calidad nutricional para la alimentación animal.

\section{Agradecimientos}

A la Universidad del Cauca, grupo de investigación ASUBAGROIN; Universidad Nacional de Colombia sede Palmira, laboratorio de nutrición animal; Sistema General de Regalías, y a la Asociación Productora y Comercializadora de Productos Acuícolas y Agrícolas de Silvia APROPESCA.

\section{Referencias}

[1] Y. J. Garcés, C. Perea, N.F. Valencia, J.L Hoyos, and J.A. Gómez, "Nutritional effect of the chemical silage of fish by-products in broiler (Gallus domesticuset al.) feeding", Cuban Journal of Agricultural Science, Vol. 49 (4), pp. 503-508, 2015.

[2] J. Llanes, A. Bórquez, J. Alcaino, y J. Toledo, "Composición físico-química y digestibilidad de los ensilajes de residuos pesqueros en el salmón del Atlántico (Salmo salar)", Revista Cubana de Ciencia Agrícola, Vol. 45 (4), pp. 417422, 2011.

[3] W. Al-Marzooqi, M. Al-Farsi, I. Kadim, O. Mahgoub, and J. Goddard, "The Effect of Feeding Different Levels of Sardine Fish Silage on Broiler Performance,
Meat Quality and Sensory Characteristics under Closed and Open-sided Housing Systems", Asian-Aust. J. Anim. Sci, Vol. 23 (12), pp. 1614-1625, 2010.

[4] S. Guzel, H. Yazlak, K. Gullu, and E. Ozturk, "The effect of feed made from fish processing waste silage on the growth of rainbow trout (Oncorhynchus mykiss)", African Journal of Biotechnology, Vol. 10 (25), pp. 5053-5058, 2011.

[5] D. T. Mach, M. D. Nguyen, and R. Nortvedt, "Effects on digestibility and growth of juvenile cobia (Rachycentron canadum) fed fish or crab silage protein", Aquaculture Nutrition, Vol. 16 (3), 305312, 2010.

[6] J. Ramírez, J. Ibarra, F. Romero, P. Rosas, J. Ulloa, K. Matsumoto, B. Vallejo, and M. Mazorra, "Preparation of Biological Fish Silage and its Effect on the Performance and Meat Quality Characteristics of Quails (Coturnix coturnix japonica)", Braz. Arch. Biol. Technol, Vol. 56 (6), pp. 1002-1010, 2013.

[7] C. M. Agudelo, y O.T. Rodrigo, "Estandarización del proceso de fermentación de ensilado biológico a partir de residuos y vísceras de tilapia roja (Oreochromis spp), producidas en el embalse "La salvajina", departamento del Cauca", Tesis de pregrado, Facultad de Ciencias Agropecuarias, Universidad del Cauca, Popayán, Colombia, 2010.

[8] L. F. Arruda, R. Borghesi, and M. Oetterer, "Use of Fish Waste as Silage - A Review", Brazilian archives of Biology and Technology, Vol. 50 (5), pp. 879-886, 2007.

[9] R. A. Bello, and Y. Fernandez, "Evaluation of biological fish silage in broiler chicken", Archivos Latinoamericanos de Nutrición, Vol. 45 (2), pp. 134-139, 1995.

[10] Microbiología de alimentos y alimentos para animales. Método horizontal para la detección y enumeración de coliformes y bacterias mesofilicas de ácido láctico. 
Técnica del número más probable, NTC 4516 y 4519, Bogotá Colombia, 1998.

[11] Microbiología. Guía general para el recuento de mohos y levaduras. Técnica de recuento de colonias $25^{\circ} \mathrm{C}$, NTC 4132, Bogotá Colombia, 2008.

[12] R. Ramasubburayan, P. Iyapparaj, K.J. Subhashini, M.N. Chandran,A.Palavesam, and G. Immanuel, "Characterization and Nutritional Quality of Formic Acid Silage Developed from Marine Fishery Waste and their Potential Utilization as Feed Stuff for Common Carp Cyprinus carpio Fingerlings", Turkish Journal of Fisheries and Aquatic Sciences, Vol. 13, pp. 281-289, 2013.

[13] Official Methods of Analysis of the Association of Official Analytical Chemists, AOAC 920.39, 934.01 and 942.04, Arlington, Virginia, USA, 1990.

[14] J. Kjeldahl, "Neue Methode zür Bestimmung des Stickstoffs in organischen Körpern", Zeitschrift für Analytische Chemie, Vol. 22 (1), pp. 366-382, 1883.

[15] Official Methods of Analysis of the Association of Official Analytical Chemists, Amino acids in feeds, AOAC 994.12, Arlington, Virginia, USA, 2000.

[16] Official Methods and Recommended Practices of the AOCS. The American Oil Chemists Society, CE 1b-89, USA, 2003.

[17] P. J. Van Soest, J.B. Robertson, and B.A. Lewis, "Methods for dietary fiber, neutral detergent fiber, and nonstarch polysaccharides in relation to animal nutrition", J. Dairy Sci, 74 (10), pp. 35833597, 1991

[18] J. Carmona. J. Montoya, y G. Castaño, "Digestibilidad aparente de cuatro concentrados empleados durante el levante Orechromis sp", Boletin de Investigaciones de Unisarc, Vol. 10 (2), pp. 15-21, 2012.

[19] S. Gonzalvo, "Métodos para la determinación de la digestibilidad in vitro de alimentos para animales monogástricos", Revista computarizada de producción porcina, Vol. 8 (2), pp. 6-10, 2001.

[20] D. B. Duncan, "Multiple ranges and multiple F Test", International Biometric Society, Vol. 11 (1), pp. 1-42, 1995.

[21] J. Llanes, A. Bórquez, J. Toledo, y J. Vega, "Digestibilidad aparente de los ensilajes de residuos pesqueros en tilapias roja (Oreochromis mossambicus x $O$. niloticus)", Zootecnia Tropical, Vol. 28 (4), pp. 499-505, 2010.

[22] C. Botero, "Aprovechamiento nutritivo de núcleos ensilados de vísceras de pollo en híbridos de cachama Piaractus brachypomus x Colossoma macropomun", Tesis de maestría, Facultad de Ciencias Agropecuarias, Universidad Nacional de Colombia sede Palmira, Palmira Colombia, 2012.

[23] M. Nascimento, K.F. Freitas, y M.V. Da Silva, "Produção e caracterização de silagens de resíduos de peixes comercializados no mercado público de Parnaíba - PI', Enciclopédia biosfera, Vol.10 (18), pp. 2450-2458, 2014.

[24] A. Botello, J. Toledo, T. García, J. Llanes, y J. De La Vega, "Conservación in vitro de tres ensilajes de pescado (Opisthonema oglinum), Caracterización físicoquímica", Revista Electrónica Granma Ciencia, Vol.14 (1), pp. 1-10, 2010.

[25] J. C. Ramírez, "Aprovechamiento de fauna de acompañamiento del camarón y subproductos pesqueros mediante la elaboración de ensilado de pescado", Tesis doctoral, Departamento de Biotecnología, Universidad Autónoma Metropolitana Unidad Iztapalapa, México D.F, 2009.

[26] E. R. Farnworth, I. Mainville, M. P, Desjardins, N. Gardner, I. Fliss, and C. Champagne, "Growth of probiotic bacteria and bifidobacteria in a soy yogurt formulation", International Journal of 
Food Microbiology, Vol. 116 (1), pp. 174181, 2007.

[27] M. Spanopoulos-Hernandez, J. T. PoncePalafox, G. Barba-Quintero, J. R. RuelasInzunza, M. R. Tiznado-Contreras, C. Hernández-González, y K. Shirai, "Producción de ensilados biológicos a partir de desechos de pescado, del ahumado de atún aleta amarilla (Thunnus albacares) y del fileteado de tilapia (Oreochromis sp), para la alimentación de especies acuícolas", Revista Mexicana de Ingeniería Química, Vol. 9 (2), pp. 167$178,2010$.

[28] D. González, y M. Marín, “Obtención de ensilado biológico a partir de los desechos del procesamiento de sardinas. Revista Científica", Revista Cientifica FCV-LUZ, Vol. XV (6), pp. 560-567, 2005.

[29] L. Betancourt, G. J. Díaz, X. Aguilar, and J. Ríos, "Efecto del ensilaje de vísceras de trucha (Oncorhynchus mykiss) sobre el comportamiento productivo y el contenido de ácidos omega-3 en hígado, muslos y pechuga, de pollos de engorde", Livestock Research for Rural Development, Vol. 17 (9), pp. 1-13, 2005.

[30] G. Wicki, E. Wiltchiensky, y L. Luchini, "Ensilados de vísceras de pescado de rio como fuente de proteína y formulas alimentarias a base de harina de soja, o de algodon, o de pluma; como sustituto total o parcial de la harina de pescado en el engorde final de pacu, en el noreste
Argentino", Paseo Colón 982-Anexo Pesca (1063), Buenos Aires Argentina, 2003.

[31] C. Perea, Y. J. Garcés, J. L. Hoyos, y N. J. Vivas, "Digestibilidad de dietas formuladas con ensilaje biológico de subproductos piscícolas para alimentación de Oreochromis spp", Revista Facultad Nacional de Agronomía, Vol. 67 (2), pp. 1148-1149, 2014.

[32] O. Fagbenro, K. Jauncey, and G. Haylor, "Nutritive valve of diets containing dried lactic acid fermented fish silage and soybean meal for juveniles Oreochromis niloticus and Clarias gariepinus", Aquat. Living Resour, Vol. 7 (2), pp. 79-85, 1994.

[33] J. Llanes, J. Toledo, L. Savón, y B. Gutiérrez, "Crecimiento de Tilapias rojas Oreochromis mossambicus x O. niloticus con dietas semi-húmedas a base de ensilados de residuos pesqueros" Mundo Pecuario, Vol. X (2), pp. 69-83, 2014.

[34] N. J. Goosen, L. F. Wet, J. F. Görgens, K. Jacobsc, and A. Bruyn, "Fish silage oil from rainbow trout processing waste asalternative to conventional fish oil in formulated diets for Mozambique tilapia Oreochromis mossambicus". Animal Feed Science and Technology, Vol. 188 (1), pp. 74-84, 2014.

[35] C. Lim, A. Mediha, D. Davis, and K. Phillip, "Effects of varied dietary lipid sources tested in tilapia stidy", Global Aquaculture Advocate, Vol. 11 (3), pp. 68-70, 2008. 